\title{
Bacterial infections in patients with liver cirrhosis: clinical characteristics and the role of $\mathrm{C}$-reactive protein
}

\author{
Melanie Deutsch, Spilios Manolakopoulos, loannis Andreadis, Markos Giannaris, George Kontos, \\ Hariklia Kranidioti, Maria Pirounaki, John Koskinas
}

National and Kapodistrian University of Athens, Hippokration General Hospital, Athens, Greece

\section{Abstract}

\section{Introduction}

Patients with cirrhosis are at high risk of developing bacterial infections, sepsis and sepsis-related death $[1,2]$. There is evidence that about one third of cirrhotic patients present with infection at hospital admission or develop infection during hospitalization [3]. However, the diagnosis of bacterial infection

$2^{\text {nd }}$ Academic Department of Internal Medicine, National and Kapodistrian University of Athens, Hippokration General Hospital, Athens, Greece

\section{Conflict of Interest: None}

Correspondence to: Melanie Deutsch, $2^{\text {nd }}$ Academic Department of Internal Medicine, National and Kapodistrian University of Athens, Hippokration General Hospital, 114 Vas. Sofias Ave., 11527 Athens, Greece, e-mail: meladeut@gmail.com

Received 18 August 2017; accepted 26 September 2017; published online 26 October 2017

DOI: https://doi.org/10.20524/aog.2017.0207 in cirrhotics is often difficult, since these patients usually present with signs of unspecific clinical deterioration and not the classical clinical characteristics of systemic inflammation, such as fever and raised white blood cell (WBC) count. The presence of portal hypertension or hepatic encephalopathy and the effect of $\beta$-blockers may modify the clinical picture and the biochemical parameters of systemic inflammatory response syndrome (SIRS). Therefore the diagnosis of bacterial infection and sepsis in patients with cirrhosis remains challenging [4]. On the other hand, one may argue that the detrimental effects of infections in patients with cirrhosis could be, at least in part, the result of delay due to difficulties in the diagnosis, since the prompt initiation of antimicrobial treatment significantly improves the prognosis and clearly reduces mortality rates [5].

The role of C-reactive protein (CRP), a well-known biomarker of inflammation in the general population, has not been clearly defined in patients with advanced liver disease. CRP is an acute-phase reactant that is mainly produced in the liver following stimulation by interleukin (IL) -1 and -6, with increased expression within the first hours after the triggering 
insult. CRP seems to play a key role in the inflammatory process and provides a link between the innate and adaptive immune systems. In everyday clinical practice, CRP is widely used as an indicator of SIRS, with levels greater than $50 \mathrm{mg} / \mathrm{L}$ being associated with sepsis [6]. Several studies in the general population have shown that CRP levels represent a useful marker that not only helps diagnose infection early, but also can predict survival [7].

CRP production might be reduced in patients with impaired liver function and decreased protein synthesis. In contrast, it was shown that patients with cirrhosis without infection had higher levels of IL- 6 and increased expression of tumor necrosis factor receptors $[8,9]$. Therefore, assessing the appropriate CRP levels that would actually help diagnose infection in patients with advanced liver disease remains difficult and there is, to date, a shortage of data dealing with this special issue.

Our aim was to evaluate the role of CRP as a diagnostic tool for bacterial infection in a group of hospitalized patients with cirrhosis. We focused on the value of a single determination of CRP, at the time of admission or on the day after, in identifying patients with infection.

\section{Patients and methods}

\section{Patients}

We evaluated a cohort of 405 admissions at the $2^{\text {nd }}$ Academic Department of Internal Medicine and Liver Unit, Hippokration General Hospital of Athens, including 327 consecutive patients with cirrhosis hospitalized between May 2006 and February 2010. One hundred six patients were excluded from our analysis because they had either incomplete medical records or a history of liver transplantation, variceal bleeding at the time of admission, infection with human immunodeficiency virus, evidence of hepatocellular carcinoma or other solid tumors, were already being treated with antibiotics, or had non-cirrhotic portal hypertension; thus, 221 patients were included in the further analysis. One hundred patients had documented bacterial infection at or during the first 3 days of hospitalization (Group 1), while 121 patients were admitted for other reasons (large volume paracentesis, banding sessions, etc.) and had no signs of infection (Group 2). Eleven patients from Group 2 developed bacterial infections after the third day of hospitalization and were excluded from further analysis.

A third group (Group 3) of 106 patients represented the control group and consisted of consecutively admitted patients with documented bacterial infections who had no history or signs of chronic liver disease.

\section{Diagnosis of bacterial infection}

On the day of admission all patients with cirrhosis followed a protocol for early diagnosis of infection, including WBC count, urine sediment, chest radiograph, blood and urine culture, ascitic fluid neutrophil count and culture in blood culture vials at the bedside. The diagnosis of spontaneous bacterial peritonitis in patients with cirrhosis was based on the neutrophil cell counts in the ascitic fluid $\left(>250 / \mathrm{mm}^{3}\right)$ regardless of the result of the ascitic fluid culture [10].

Urinary tract infection was diagnosed in cases with a positive culture of $>10^{5}$ colonies $/ \mathrm{mL}$ urine, with no more than 2 species of organisms, and associated with one of the following symptoms: fever $>38^{\circ} \mathrm{C}$, dysuria or suprapubic tenderness.

Patients were considered to have pulmonary bacterial infection if they had dyspnea or cough and a new radiographic infiltrate for which a nonbacterial or noninfectious complication was unlikely according to the clinical circumstances. Pulmonary bacterial infection was clinically suspected when no causal agent was found, or was clearly documented when a bacterial pathogen was isolated in sputum, bronchial aspirate, bronchoalveolar lavage fluid, blood or pleural fluid. Bacteremia was defined when blood cultures were positive and clinical signs or symptoms of infection were present, but without any other recognized cause.

In all patients demographic and clinical data were collected together with routine laboratory data on the first day after admission.

CRP levels were determined using a commercial turbidimetric immunoassay with normal values below $5 \mathrm{mg} / \mathrm{L}$.

\section{Diagnosis and staging of cirrhosis}

The diagnosis of cirrhosis was based on liver biopsy, FibroScan, or a combination of clinical, biochemical and imaging data. Liver failure severity was established by the CPS and the model for end-stage liver disease (MELD) scores $[11,12]$.

\section{Statistical analysis}

Data were analyzed using STATA/IC 11.0 (StataCorp). Data are presented as the mean \pm standard deviation (95\% confidence interval [CI]) for normal distributions and median and interquartile range for non-normal data. Continuous variables were analyzed using the Student's $t$-test or Mann-Whitney $U$ test, depending on the normality of their distribution. Categorical values were analyzed using the chi-square test. Logistic regression was used for univariate analysis. A stepwise binary logistic regression method ( $\mathrm{pe}=0.05$ and $\mathrm{pr}=0.10$ ) was used to identify predictive factors for the diagnosis of bacterial infection. Cutoff values for CRP were determined by receiver operating characteristic (ROC) curve distribution. Sensitivity, specificity, positive and negative predictive values were also obtained. Two-tailed P-values $<0.005$ were considered to be statistically significant.

The study was conducted in compliance with the Declaration of Helsinki and was approved by the hospital's ethics committee. 


\section{Results}

Two hundred ten consecutive hospitalized patients with liver cirrhosis of different etiologies were included in the analysis. Patient characteristics in the three study groups are shown in Table 1. Viral hepatitis was the cause of chronic liver disease in $87(41.4 \%)$ patients, alcohol consumption in $83(39.5 \%)$, nonalcoholic fatty liver disease in 4 (1.9\%), autoimmune liver diseases (autoimmune hepatitis, primary biliary cirrhosis) in $6(3 \%)$ patients, while $30(14.3 \%)$ had cryptogenic cirrhosis.

One hundred patients ( $71 \%$ male, age $63 \pm 14.6$ years) had documented bacterial infection at admission or during the first 3 days of admission (Group 1) and 110 (78\% male, age
$61.4 \pm 12.7$ years) were hospitalized for other reasons (Group 2). The control group (Group 3) included 106 patients (51\% male, age $71.4 \pm 16$ years) who had proven bacterial infections without history or signs of chronic liver disease.

The most common infections in both groups of patients (cirrhotics and non-cirrhotics) were infections of the urogenital tract (pyelonephritis, prostatitis, pelvic inflammatory disease) in 66/206 (32\%), respiratory system (pneumonia, bronchopneumonia) in 41/206 (20\%), or gastrointestinal tract (cholecystitis, cholangitis, gastroenteritis) in 11/206 (5.3\%). Among the cirrhotic patients 45/100 (45\%) presented with clinical and laboratory signs of spontaneous bacterial peritonitis. A total of $62 / 206(30 \%)$ of the patients

Table 1 Comparison of the characteristics of the patients included in the three study groups

\begin{tabular}{|c|c|c|c|c|}
\hline Patient characteristics & $\begin{array}{c}\text { Group } 1 \\
\text { Cirrhotic patients with } \\
\text { bacterial infection } \\
\mathrm{n}=100\end{array}$ & $\begin{array}{c}\text { Group } 2 \\
\text { Cirrhotic patients without } \\
\text { bacterial infection } \\
\mathrm{n}=110\end{array}$ & $\begin{array}{c}\text { Group 3-Control } \\
\text { Patients with bacterial } \\
\text { infection without cirrhosis } \\
n=106\end{array}$ & P-value \\
\hline Age, mean $\pm S D$ & $63 \pm 14.6$ & $61.4 \pm 12.7$ & $71.4 \pm 16$ & 0.026 \\
\hline $\begin{array}{l}\text { Sex, male/female } \\
(\% \text { male })\end{array}$ & $71 / 29(71 \%)$ & $86 / 24(78 \%)$ & $71 / 35(67 \%)$ & 0.17 \\
\hline $\begin{array}{l}\text { Cause of cirrhosis n, (\%) } \\
\text { Viral } \\
\text { Alcoholic } \\
\text { NASH } \\
\text { Autoimmune } \\
\text { Cryptogenic }\end{array}$ & $\begin{array}{c}44(44 \%) \\
38(38 \%) \\
0 \\
4(4 \%) \\
14(14 \%)\end{array}$ & $\begin{array}{c}43(39 \%) \\
45(40.9 \%) \\
4(3.6 \%) \\
2(1.8 \%) \\
16(14.5 \%)\end{array}$ & $\begin{array}{l}0 \\
0 \\
0 \\
0 \\
0\end{array}$ & $\begin{array}{c}0.5 \\
0.67 \\
0.12 \\
0.4 \\
1\end{array}$ \\
\hline $\begin{array}{l}\text { Child-Pugh* } \\
\text { A } \\
\text { B } \\
\text { C }\end{array}$ & $\begin{array}{l}14(14 \%) \\
36(36 \%) \\
50(50 \%)\end{array}$ & $\begin{array}{l}32(29 \%) \\
43(39 \%) \\
35(32 \%)\end{array}$ & $\begin{array}{l}0 \\
0 \\
0\end{array}$ & $\begin{array}{c}0.008 \\
0.43 \\
0.104\end{array}$ \\
\hline Mean MELD score ${ }^{* *}$ & $14.5 \pm 5.8$ & $8.3 \pm 2.6$ & ND & 0.0001 \\
\hline $\begin{array}{l}\text { Bacterial infections, } \mathrm{n}(\%) \\
\text { Bacteremia } \\
\text { Cholecystitis/cholangitis } \\
\text { Dermal } \\
\text { Gastroenteritis } \\
\text { Respiratory } \\
\text { Uro-genital tract } \\
\text { Spontaneous bacterial peritonitis }\end{array}$ & $\begin{array}{c}20(20 \%) \\
3(3 \%) \\
6(6 \%) \\
4(4 \%) \\
9(9 \%) \\
19(19 \%) \\
45(45 \%)\end{array}$ & $\begin{array}{l}0 \\
0 \\
0 \\
0 \\
0 \\
0 \\
0\end{array}$ & $\begin{array}{c}32(30 \%) \\
2(1.9 \%) \\
3(2.8 \%) \\
2(1.9 \%) \\
32(30.2 \%) \\
47(44.3 \%) \\
0\end{array}$ & $\begin{array}{c}0.11 \\
0.67 \\
0.32 \\
0.43 \\
<0.001 \\
<0.001 \\
<0.001\end{array}$ \\
\hline $\begin{array}{l}\text { Fever }>37^{\circ} \mathrm{C}, \mathrm{n}(\%) \\
\text { Fever } \geq 38^{\circ} \mathrm{C}, \mathrm{n}(\%) \\
\text { Mean body temperature, }{ }^{\circ} \mathrm{C}\end{array}$ & $\begin{array}{c}47 / 100(47 \%) \\
31 / 100(31 \%) \\
37.4 \pm 0.9\end{array}$ & $\begin{array}{c}0 / 110 \\
0 / 110 \\
36.5 \pm 0.08\end{array}$ & $\begin{array}{c}90 / 106(85.5 \%) \\
79 / 106(74.5 \%) \\
38.3 \pm 1\end{array}$ & $\begin{array}{l}0.01 \\
0.01 \\
0.01\end{array}$ \\
\hline $\begin{array}{l}\text { White blood cell count, } / \mathrm{mm}^{3} \\
(\text { mean } \pm \text { SD })\end{array}$ & $7567.8 \pm 4241.5$ & $6121 \pm 2518$ & $12842.3 \pm 7011.3$ & 0.02 \\
\hline Mean hematocrit, $\%$ & $32.2 \pm 5.7$ & $32.9 \pm 5.7$ & $36.3 \pm 6.2$ & 0.57 \\
\hline Mean fibrinogen & $301.7 \pm 170.4$ & $328 \pm$ & $649.5 \pm 249.7$ & 0.27 \\
\hline Mean albumin & $3.1 \pm 0.6$ & $3.2 \pm 0.6$ & $3.5 \pm 0.7$ & 0.001 \\
\hline Mean CRP mg/dL & $34 \pm 38.8$ & $5.7 \pm 7.3$ & $147 \pm 95$ & 0.001 \\
\hline
\end{tabular}

*The Child-Pugh score was calculated on the basis of the serum bilirubin and albumin levels, the prothrombin time, and the presence and degree of ascites or encephalopathy. The sum of the scores provides the Child-Pugh score, which corresponds to a Child-Pugh grade of A (range: 5-6), B (range: 7-9), or C (range: $10-15)$

${ }^{* *}$ MELD score was calculated based on bilirubin, creatinine and international normalized ratio using the MELD score calculator (http://www.mayoclinic.org/ medical-professionals/model-end-stage-liver-disease)

NASH, non-alcoholic steatohepatitis; CRP, C-reactive protein; MELD, model for end-stage liver disease; SD, standard deviation 
with infection $(20 \%$ of the cirrhotics and $30 \%$ of the noncirrhotics) had positive blood cultures. Among the cirrhotics, $66 \%$ of the patients had Gram-negative and $33 \%$ Gram-positive bacteremia.

\section{Clinical data}

Among the 206 patients with bacterial infection, 146 (66\%) presented with a body temperature $(\mathrm{BT}) \geq 37^{\circ} \mathrm{C}$; significantly fewer patients with than without cirrhosis had $\mathrm{BT} \geq 37^{\circ} \mathrm{C}$ : $56 / 100$ (56\%) vs. $90 / 106$ (85.5\%), $\mathrm{P}=0.01$. All patients with cirrhosis and without bacterial infection had $\mathrm{BT}<37^{\circ} \mathrm{C}$ at presentation. High fever at presentation $\left(\mathrm{BT} \geq 38^{\circ} \mathrm{C}\right)$ was observed in $110 / 206$ patients (53\%), 31/100 (31\%) of the cirrhotics and 79/106 (74.5\%) of the non-cirrhotics $(\mathrm{P}=0.01)$.

A statistically significant difference among the three groups regarding the mean BT at presentation was documented. Patients in Group 1 had lower mean BT compared to those of Group 3: $37.4 \pm 0.9^{\circ} \mathrm{C}$ (range: $36-40^{\circ} \mathrm{C}$ ) vs. $38.35 \pm 1.0^{\circ} \mathrm{C}$ (range: $35.7-41^{\circ} \mathrm{C}$ ). Patients with cirrhosis without infection presented with normal BT $\left(36.5 \pm 0.08^{\circ} \mathrm{C}\right)$.

Patients with liver cirrhosis had a mean MELD score of $11 \pm 5.7$ (range: 5-23), while patients with infection had a significantly higher MELD score at the time of admission compared to those without evidence of infection: Group 1: $14.5 \pm 5.8$ vs. Group 2: $8.34 \pm 2.6(\mathrm{P}<0.001)$.

There was a significant difference between the mean MELD score in patients with cirrhosis and bacterial infections who presented with fever $\left(\mathrm{BT} \geq 37^{\circ} \mathrm{C}\right)$ and those who did not $\left(\mathrm{BT}<37^{\circ} \mathrm{C}\right)$ : $13.2 \pm 5.1$ vs. $16.07 \pm 6.4$, respectively $(\mathrm{P}=0.015)$. Moreover, patients with high fever $\left(\mathrm{BT}>38^{\circ} \mathrm{C}\right)$ had a lower mean MELD score (13.8 \pm 4.6$)$.

\section{Laboratory data}

\section{WBC count}

There was a significant difference in mean WBC count among the three study groups: 6.92 (range: 4.60-9.38) $\times 10^{3} / \mathrm{mm}^{3}$ in patients with cirrhosis and bacterial infection vs. 5.75 (range: $4.07-7.70) \times 10^{3} / \mathrm{mm}^{3}(\mathrm{P}=0.02)$ in cirrhotic patients without infection and 11.28 (range: $8.40-15.20) \times 10^{3} / \mathrm{mm}^{3}$ in non-cirrhotic patients with infection $(\mathrm{P}<0.001)$. Patients with alcoholic cirrhosis had a higher mean WBC count even without infection $7.23 \pm 2.8 \times 10^{3} / \mathrm{mm}^{3}$ and no statistically significant difference was found when compared with alcoholic cirrhotics with infection $8.47 \pm 4.58 \times 10^{3} / \mathrm{mm}^{3}(\mathrm{P}=0.13)$.

\section{CRP}

The mean CRP value in patients with cirrhosis and infection was $34 \pm 38.8 \mathrm{mg} / \mathrm{L}$, compared to $147 \pm 95 \mathrm{mg} / \mathrm{L}$ in noncirrhotic patients with infection $(\mathrm{P}<0.001)$ and $5.7 \pm 7.3 \mathrm{mg} / \mathrm{L}$ in the group of patients who had cirrhosis without infection
$(\mathrm{P}<0.001$, Table 1$)$. Moreover, a statistically significant number, $19 / 100$ (19\%), of the cirrhotic patients had normal CRP levels ( $<5 \mathrm{mg} / \mathrm{L})$, despite documented bacterial infection, compared with $2 / 106(1.9 \%)$ of the non-cirrhotic patients $(\mathrm{P}<0.001)$. When patients who presented with $\mathrm{BT}>38^{\circ} \mathrm{C}$ were taken into account, the difference between the CRP levels among cirrhotic and non-cirrhotic patients became non-significant $(\mathrm{P}=0.29)$.

Regarding the etiology of cirrhosis, patients with bacterial infections and autoimmune liver disease presented with a lower mean CRP level $(1.75 \pm 0.07 \mathrm{mg} / \mathrm{L})$ compared to patients with cirrhosis due to viral $(6.3 \pm 1.3 \mathrm{mg} / \mathrm{L})$ or alcoholic $(5.35 \pm 0.9 \mathrm{mg} / \mathrm{L})$ etiology $(\mathrm{P}=0.26)$. Among the cirrhotic patients who had no signs of infection, $33.3 \%$ (all with alcoholic liver disease) presented with $\mathrm{CRP}>5 \mathrm{mg} / \mathrm{L}(\max 40 \mathrm{mg} / \mathrm{L})$. In the univariate analysis, serum CRP concentrations, WBC and MELD score were significantly associated with bacterial infection in cirrhotics (Table 2). Multivariate analysis, however, showed that only CRP levels and MELD score were associated significantly with infection (Table 3 ).

In cirrhotic patients with the same MELD score, the probability of infection increased by $8 \%$ for each one-unit increase in CRP concentrations. Likewise, for each one-unit increase in MELD score the probability of infection increased by $40 \%$ in patients with the same CRP value.

Using ROC curves, the probability of infection in cirrhotics was estimated according to the CRP levels. Specifically, a cutoff CRP level $>10 \mathrm{mg} / \mathrm{L}$ indicated the presence of infection with a sensitivity of $68 \%$, a specificity of $84.55 \%$ and an area under the ROC curve (AUROC) of 0.8197.

The best cutoff level for CRP according to the severity of the liver disease, determined by the CPS, showed a slight variation, with lower cutoff levels in more advanced liver disease. In patients with advanced liver disease (CPS-C) a CRP cutoff level of 5.78 was found to be significant in identifying patients who might have bacterial infection (Table 4, Fig. 1).

Table 2 Univariate analysis: CRP levels, WBC count and MELD score were significantly associated with bacterial infection in cirrhotic patients

\begin{tabular}{lccc}
\hline Variable & Odds Ratio & $95 \%$ CI & P-value \\
\hline CRP & 1.11 & $1.07-1.15$ & $<0.001$ \\
WBC & 1.00 & $1.00-1.00$ & 0.004 \\
MELD & 1.43 & $1.29-1.59$ & $<0.001$ \\
\hline
\end{tabular}

CRP, C-reactive protein; $W B C$, white blood cell count; $M E L D$, model for end-stage liver disease; 95\%CI, 95\% confidence interval

Table 3 Multivariate analysis: CRP levels and MELD score were significantly associated with the presence of bacterial infection in cirrhotic patients

\begin{tabular}{lccc}
\hline Variable & Odds Ratio & $95 \% \mathrm{CI}$ & P-value \\
\hline CRP & 1.08 & $1.04-1.12$ & $<0.001$ \\
MELD & 1.39 & $1.23-1.57$ & $<0.001$ \\
\hline
\end{tabular}

CRP, C-reactive protein; MELD, model for end-stage liver disease; $95 \% C I, 95 \%$ confidence interval 
Table 4 Cutoff levels for CRP according to the severity of the liver disease

\begin{tabular}{lcccc}
\hline Child-Pugh & CRP cutoff & Sensitivity & Specificity & Area under the ROC curve \\
\hline A & 21.3 & 35.71 & 93.75 & 0.6641 \\
B & 17 & 55.56 & 95.00 & 0.8127 \\
C & 5.78 & 86.00 & 74.29 & 0.8794 \\
\hline
\end{tabular}

CRP, C-reactive protein; $R O C$, receiver operating characteristic

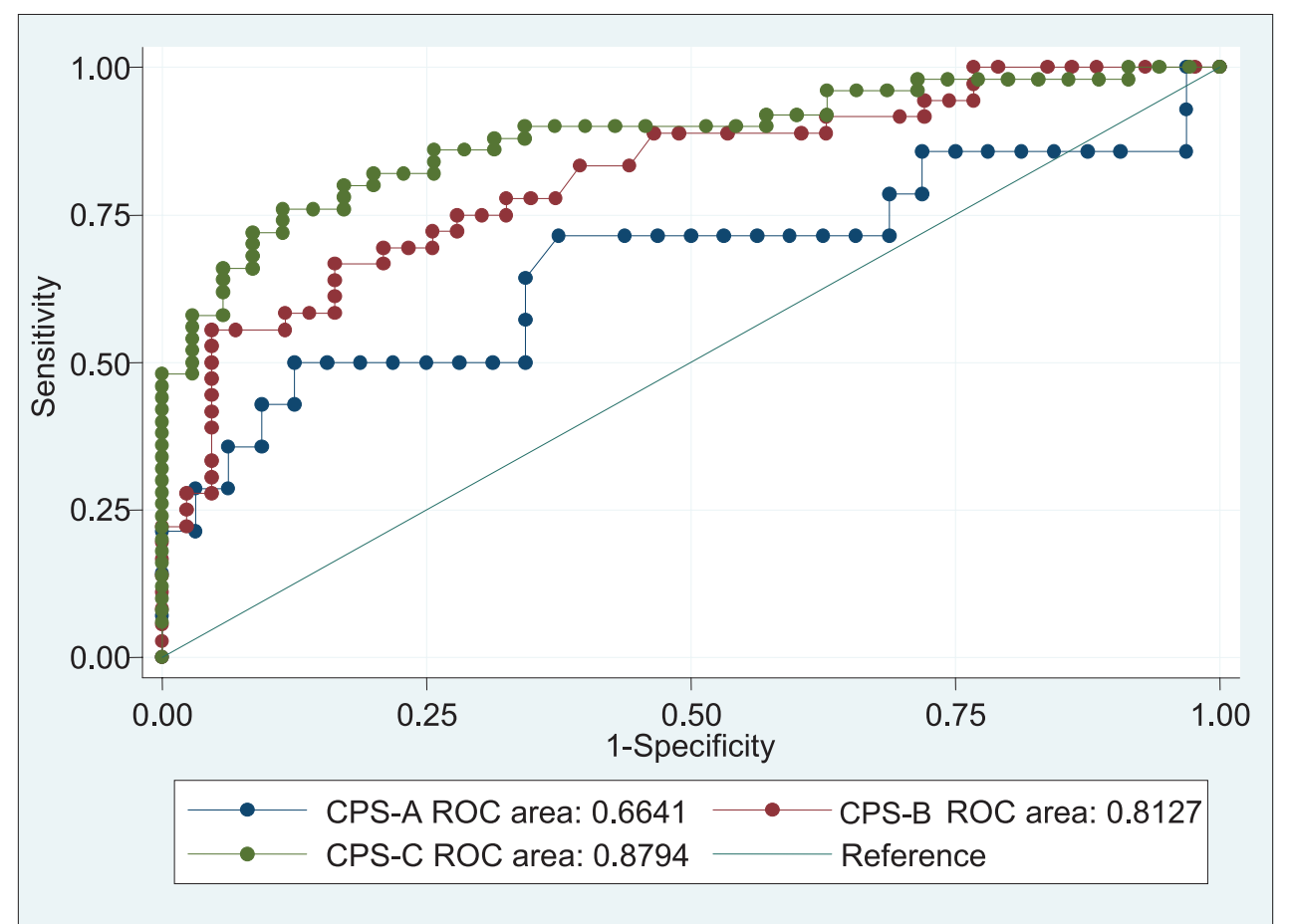

Figure 1 ROC curve representing the diagnostic value of CRP according to the three different disease stages as represented by the CPS CRP, C-reactive protein; ROC, receiver operating characteristic; CPS, Child-Pugh score

\section{Discussion}

Bacterial infections in patients with cirrhosis represent a major cause of hospitalization and a common reason for clinical deterioration or death [13-15]. Immediate treatment initiation is required, but clear clinical and laboratory data supporting the diagnosis are lacking. Our study aimed to evaluate the characteristics of these patients to set a clinical context that could help improve clinicians' skills in detecting early bacterial infection in patients with liver function impairment.

We performed a retrospective analysis of prospectively collected data from 210 consecutive hospitalized patients with cirrhosis. We compared clinical and laboratory parameters between cirrhotics admitted to the hospital with and without infection, and we also included a control group of 106 patients who had evidence of infection without chronic liver disease.

Regarding the clinical data, several reviews underline the lack of typical signs of infection and inflammatory response in patients with advanced liver disease; however, they are based on a limited number of studies, most of which were retrospective and published some decades ago [16]. In a more recent study [1], the prevalence, incidence and clinical relevance of bacterial infection were documented for a total of 405 admissions (361 cirrhotic patients). It was underlined that infections are common and may also occur during hospitalization for other reasons. Interestingly, $46 \%$ of the patients with infections were asymptomatic.

Our data confirms these previous findings, showing that the typical clinical symptoms or signs of bacterial infection were present in less than half of our cirrhotic patients. More specifically, despite bacterial infection, only one third of our patients had fever $>38^{\circ} \mathrm{C}$ at admission, while most of them had WBC within normal ranges. This was eventually attributed to a "relative" increase in WBC count to normal values in patients with known leucopenia due to the presence of hypersplenism. In this context, patients with alcoholic liver disease form a special group. Although we did not include patients with acute alcoholic hepatitis, patients with alcoholic cirrhosis also present with relative higher $\mathrm{WBC}$ due to neutrophil priming [17], even in the case of hypersplenism. Indeed, we found no statistically significant difference in WBC between alcoholic cirrhotics with or without infections, indicating that 
WBC are unable to respond to further bacterial challenge in these patients. However, regardless of the WBC, it is well known that alcoholic patients present with defective neutrophil function and are especially prone to develop infections [18]; thus, other biomarkers are needed in these patients.

It is noteworthy that the severity of liver disease was found to inversely correlate with the presence of typical clinical presentation; patients with infection and fever had significantly lower MELD scores compared with those without fever: the more severe the liver disease, the less typical the clinical symptoms and signs. Therefore, in everyday clinical practice, high suspicion is needed when dealing with patients who present with signs of unexplained worsening of their liver function (increase in MELD score), despite the absence of fever or leukocytosis.

How can the quantitative assessment of CRP be helpful in this context? CRP measurement is a cheap and practical test, widely used as a biomarker of infection but also noninfectious inflammation in many disease entities [19]. However, it has been proven quite nonspecific, having an established diagnostic and prognostic value especially in patients with sepsis.

Indeed, the role of CRP in diagnosing bacterial infections in patients with impaired liver function is in conflict with studies debating whether it really represents a reliable marker [20]. Other studies have correlated CRP as a factor independently associated with mortality in patients with liver disease [21]. The different design and methodology of these studies might be an explanation for the contradictory results.

In our cohort, there was a significant difference between CRP values at presentation between cirrhotic and non-cirrhotic patients with infections, with cirrhotics having lower values even in severe cases of bacterial infection with bacteremia; 19/100 patients with cirrhosis and infection had CRP values within normal values. These results may lead to the apparent conclusion that CRP cannot represent a reliable marker of early diagnosis of infection in patients with cirrhosis.

But what about values of CRP that are "near normal", and what does "normal" mean in patients who have impaired protein synthesis? In a further analysis, we tried to define a useful "low" cutoff level for CRP, through the generation of ROC curves. A level of $10 \mathrm{mg} / \mathrm{L}$ was found to indicate infection with a sensitivity of $68 \%$, a specificity of $84.55 \%$ and an AUROC of 0.8197 . This cutoff level is comparable with the results of one study from Hungary [22] (9.2 mg/L AUC 0.93) but is much lower than those in other reports $(6.5-80 \mathrm{mg} / \mathrm{L})[23,24]$. The Hungarian study, like ours, involved a large number of patients from everyday clinical practice, while the other studies included smaller cohorts of patients with severe infectious episodes (patients in the intensive care unit or with sepsis).

Furthermore, analyzing the diagnostic accuracy of CRP levels according to the severity of the liver disease, we found an indirect proportional relationship between the CRP cutoff level and CPS: the higher the CPS, the lower the diagnostic CRP cutoff level (CPS-A: $21.3 \mathrm{mg} / \mathrm{L}$, CPS-B: $17 \mathrm{mg} / \mathrm{L}, \mathrm{CPS}-\mathrm{C}$ : $5.8 \mathrm{mg} / \mathrm{L}$ ). This finding has important clinical implications, showing that in patients with advanced liver disease the smallest CRP elevation ( $5.8 \mathrm{mg} / \mathrm{L}$ with normal value $<5 \mathrm{mg} / \mathrm{L}$ ) could be a sign of bacterial infection requiring antibiotic initiation.

\section{Summary Box}

\section{What is already known:}

- The diagnosis of bacterial infection in cirrhotic patients is difficult because of the absence of classical clinical signs of systemic inflammation

- C-reactive protein (CRP) is a well-known biomarker of inflammation in the general population

- CRP production might be reduced in patients with impaired liver function and its role has not been clearly defined in patients with advanced liver disease

\section{What the new findings are:}

- Typical signs of infection and systematic inflammation were observed only in approximately $50 \%$ of the patients with advanced liver disease

- A cutoff level of $\mathrm{CRP}>10 \mathrm{mg} / \mathrm{dL}$ was found to indicate the presence of infection in cirrhotic patients with a sensitivity of $68 \%$, specificity $84.5 \%$ and an area under the receiver operating characteristic curve of 0.82

- Severity of liver disease, determined by ChildPugh score, affects CRP values and lower levels are indicative of infection

Other studies also reported that for more advanced liver disease the diagnostic capacity of CRP was lower for the same CRP level, with AUROC values decreasing in direct relation to the severity of the liver disease [15]. In this context, and for practical reasons, we took a step forward in suggesting a possible cutoff level for each CPS stage.

Another biomarker that was found to correlate with bacterial infections was procalcitonin [25]. When studied in patients with liver disease and compared with CRP an acceptable accuracy has been reported [26]. However, procalcitonin is not an easy tool for routine use in everyday clinical practice.

In conclusion, patients with cirrhosis and bacterial infections usually present with a nonspecific acute phase response, making classical findings such as fever and high WBC of little help in diagnosis. On the other hand, CRP with a cutoff value of $10 \mathrm{mg} / \mathrm{dL}$ may be a useful clinical marker of infection. Moreover, CRP cutoff levels were found to differ according to the severity of liver disease. Although these findings could be helpful in everyday practice, the decision to start antibiotics must be individualized and not be based only on a certain CRP level, but on the right clinical suspicion, the stability of the patient's clinical condition, the presence of comorbidity and the risk of death or complications, issues that might still remain difficult for the treating physician. 


\section{References}

1. Borzio M, Salerno F, Piantoni L, et al. Bacterial infection in patients with advanced cirrhosis: a multicentre prospective study. Dig Liver Dis 2001;33:41-48.

2. Arvaniti V, D'Amico G, Fede G, et al. Infections in patients with cirrhosis increase mortality four-fold and should be used in determining prognosis. Gastroenterology 2010;139:1246-1256, 1256.e1-e5.

3. Fernández J, Navasa M, Gómez J, et al. Bacterial infections in cirrhosis: epidemiological changes with invasive procedures and norfloxacin prophylaxis. Hepatology 2002;35:140-148.

4. Pieri G, Agarwal B, Burroughs AK. C-reactive protein and bacterial infection in cirrhosis. Ann Gastroenterol 2014;27:113-120.

5. Fernández J, Gustot T. Management of bacterial infections in cirrhosis. J Hepatol 2012;56 (Suppl 1):S1-S12.

6. Póvoa P. C-reactive protein: a valuable marker of sepsis. Intensive Care Med 2002;28:235-243.

7. Lobo SM, Lobo FR, Bota DP, et al. C-reactive protein levels correlate with mortality and organ failure in critically ill patients. Chest 2003;123:2043-2049.

8. Tilg H, Wilmer A, Vogel W, et al. Serum levels of cytokines in chronic liver diseases. Gastroenterology 1992;103:264-274.

9. Le Moine O, Devière J, Devaster JM, et al. Interleukin-6: an early marker of bacterial infection in decompensated cirrhosis. J Hepatol 1994;20:819-824.

10. Runyon BA; Practice Guidelines Committee, American Association for the Study of Liver Diseases (AASLD). Management of adult patients with ascites due to cirrhosis. Hepatology 2004;39:841-856.

11. Cholongitas E, Papatheodoridis GV, Vangeli M, Terreni N, Patch D, Burroughs AK. Systematic review: The model for endstage liver disease-should it replace Child-Pugh's classification for assessing prognosis in cirrhosis? Aliment Pharmacol Ther 2005;22:1079-1089.

12. Christensen E. Prognostic models including the Child-Pugh, MELD and Mayo risk scores-where are we and where should we go? J Hepatol 2004;41:344-350.

13. Jalan R, Fernandez J, Wiest R, et al. Bacterial infections in cirrhosis: a position statement based on the EASL Special Conference 2013. J Hepatol 2014;60:1310-1324.
14. Wong F, Bernardi M, Balk R, et al; International Ascites Club. Sepsis in cirrhosis: report on the $7^{\text {th }}$ meeting of the International Ascites Club. Gut 2005;54:718-725.

15. Wiest R, Garcia-Tsao G. Bacterial translocation (BT) in cirrhosis. Hepatology 2005;41:422-433.

16. Caly WR, Strauss E. A prospective study of bacterial infections in patients with cirrhosis. J Hepatol 1993;18:353-358.

17. Stanley AJ, MacGregor IR, Dillon JF, Bouchier IA, Hayes PC. Neutrophil activation in chronic liver disease. Eur J Gastroenterol Hepatol 1996;8:135-138.

18. Fiuza C, Salcedo M, Clemente G, Tellado JM. In vivo neutrophil dysfunction in cirrhotic patients with advanced liver disease. J Infect Dis 2000;182:526-533.

19. Castelli GP, Pognani C, Meisner M, Stuani A, Bellomi D, Sgarbi L. Procalcitonin and C-reactive protein during systemic inflammatory response syndrome, sepsis and organ dysfunction. Crit Care 2004;8:R234-R242.

20. Bota DP, Van Nuffelen M, Zakariah AN, Vincent JL. Serum levels of C-reactive protein and procalcitonin in critically ill patients with cirrhosis of the liver. J Lab Clin Med 2005; 146:347-351.

21. Cervoni JP, Thévenot T, Weil D, et al. C-reactive protein predicts short-term mortality in patients with cirrhosis. J Hepatol 2012;56:1299-1304.

22. Papp M, Vitalis Z, Altorjay I, et al. Acute phase proteins in the diagnosis and prediction of cirrhosis associated bacterial infections. Liver Int 2012;32:603-611.

23. Lin ZY, Chuang WL, Dai CY, et al. Clinical application of serum C-reactive protein measurement in the detection of bacterial infection in patients with liver cirrhosis. Kaohsiung J Med Sci 2002;18:121-126.

24. Tsiakalos A, Karatzaferis A, Ziakas P, Hatzis G. Acute-phase proteins as indicators of bacterial infection in patients with cirrhosis. Liver Int 2009;29:1538-1542.

25. Qu J, Feng P, Luo Y, Lü X. Impact of hepatic function on serum procalcitonin for the diagnosis of bacterial infections in patients with chronic liver disease: A retrospective analysis of 324 cases. Medicine (Baltimore) 2016;95:e4270.

26. Lin KH, Wang FL, Wu MS, et al. Serum procalcitonin and C-reactive protein levels as markers of bacterial infection in patients with liver cirrhosis: a systematic review and meta-analysis. Diagn Microbiol Infect Dis 2014;80:72-78. 